\title{
PENGUKURAN TINGKAT KESIAPAN PENERAPAN E-LEARNING MENGGUNAKAN TRI (TECHNOLOGY READINESS INDEX), STUDI KASUS: UIN SUSKA RIAU
}

\author{
Angraini, Dedet Suryadi \\ Sistem Informasi, Sains dan Teknologi, UIN Sultan Syarif Kasim Riau \\ Jl. HR. Subrantas Km.15 Panam, Pekanbaru, Riau \\ E-mail: angraini@uin-suska.ac.id
}

\begin{abstract}
Measuring the level of readiness the user in using a new technology will affect the level of success of the implementation of these technologies. Readiness of a new technology affect the user to use the technology, as is the case in e-learning UIN Suska Riau managed by Computer Center UIN Suska (PUSKOM). Methods that can be used to measure the readiness of organizations in using technology is technology readiness index (TRI). TRI is an index to measure the user's readiness to accept and use new technologies to achieve the goal in daily life and work. TRI dimensions used in this study is optimism, innovative, discomfort, and insecurity. In the questionnaire in addition using descriptive statistics and index criteria Aydin Tascii. By using the index criteria set by Aydin Tascii, can be determined the value of the level of preparedness of the implementation of e-learning in the Faculty of Science and Technology is 3.36, which means Not Ready, need preparation of some aspects to achieve successful implementation of e-learning
\end{abstract}

\section{Abstrak}

Pengukuran tingkat kesiapan pengguna dalam menggunakan sebuah teknologi baru akan mempengaruhi tingkat keberhasilan penerapan teknologi tersebut. Kesiapan sebuah teknologi baru mempengaruhi pengguna untuk menggunakan teknologi, seperti yang terjadi pada e-learning UIN Suska Riau yang dikelola oleh Pusat Komputer UIN SUSKA (PUSKOM). metode yang dapat digunakan untuk mengukur kesiapan organisasi dalam menggunakan teknologi adalah technology readiness index (TRI). TRI merupakan indeks untuk mengukur kesiapan pengguna untuk menerima dan menggunakan teknologi baru untuk mencapai tujuan dalam kehidupan sehari-hari dan pekerjaan. Dimensi TRI yang digunakan dalam penelitian ini adalah optimism, inovatif, ketidaknyamanan, dan ketidakamanan. Dalam kuesioner selain menggunakan statistic deskriptif dan kriteria index Aydin Tascii. Dengan menggunakan kriteria indeks yang telah ditetapkan oleh Aydin Tascii, maka dapat ditentukan nilai tingkat kesiapan penerapan e-learning di fakutas Sains dan Teknologi adalah 3,36 yang artinya Not Ready, membutuhkan/ memerlukan persiapan beberapa aspek untuk mencapai keberhasilan penerapan e-learning.

Kata kunci: kesiapan, elearning, teknologi, pengguna, index

\section{PENDAHULUAN}

Pemanfaaatan internet di dunia penting telah menjadi bagian yang sangat penting. Kemudahan akses dan tidak adanya keterbatasan ruang dan waktu menjadikan internet sebagai salah satu solusi dalam dunia pendidikan. Salah satu aplikasi yang digunakan untuk pendidikan adalah aplikasi e-learning. Dengan adanya e-learning dapat mempermudah proses belajar mengajar. Penerapan e-learning dalam dunia pendidikan bukanlah sebuah hal yang mudah, banyak factor yang perlu diperhatikan. Factor yang perlu diperhatikan dari sisi infrastruktur, organisasi dan kesiapan penggunanya. Penguku-ran tingkat kesiapan pengguna dalam menggu-nakan sebuah teknologi baru akan mempengaruhi tingkat keberhasilan penerapan teknologi tersebut.
Dalam penelitian yang dilakukan oleh alak dan alnawas, penerapan e-learning dipengaruhi oleh perspektif pengguna, perspektif kemudahan, pengetahuan penggunaan computer, dukungan manajemen dan tujuan penerapan e-learning itu sendiri.

Ada beberapa alasan yang menyebabkan elearning sulit diterapkan, antara lain:

1. Pengembangan sistem yang tidak sesuai dengan kebutuhan infrastruktur dan peraltan yang mendukung penerapan e-learning

2. Kurangnya pelatihan yang dikhususkan untuk masing - masing level yang terlibat dalam elearning

3. Tidak adanya peningkatan yang disesuaikan dengan kebutuhan informasi, kualitas pendidikan dan layanan. 
Dalam pengembangan e-learning dukungan organisasi sangat diperlukan, serta dukungan dari pihak- pihak lain yang terkait. Salah satu metode yang dapat digunakan untuk mengukur kesiapan organisasi dalam menggunakan tekno-logi adalah technology readiness index (TRI). TRI merupakan indeks untuk mengukur kesiapan pengguna untuk menerima dan menggunakan teknologi baru untuk mencapai tujuan dalam kehidupan sehari-hari dan pekerjaan. Kesiapan sebuah teknologi baru mempengaruhi pengguna untuk menggunakan teknologi, seperti yang terjadi pada e-learning UIN Suska Riau yang dikelola oleh Pusat Komputer UIN SUSKA (PUSKOM). E-learning telah dikem-bangkan pada tahun 2009, dan langsung diuji cobakan pada fakultas tarbiyah dan keguruan. Pada tahap uji coba telah mengalami masalah terkait infrastruktur dan kesiapan pengguna. Latar belakang pengguna yang belum terbiasa dengan computer menyebabkan uji coba sistem tidak berjalan lancer. Kemudian aplikasi e-learning dikembangkan ulang pada tahun 2013 dan kembali diuji cobakan pada fakultas sains dan teknologi. Kendala kembali ditemukan pada insfrastruktur pendukung dan belum adanya regulasi. Dengan adanya masalah dalam uji coba e-learning maka untuk itu perlu dilakukan pengukuran kesiapan penerapan e-learning. Dengan mengetahui kesiapan dan pengguna, akan mengurangi masalah dalam penerapan e-learning.

\subsection{E-Learning}

Menurut Darin E. Hartley "E-Learning merupakan suatu jenis belajar mengajar yang memungkinkan tersampaikannya bahan ajar ke siswa dengan menggunakan media Internet, Intranet atau media jaringan komputer lainnya". LearnFrame.Com dalam Glossary of eLearning Terms [Glossary, 2001] menyatakan suatu definisi yang lebih luas bahwa: "E-Learning adalah sistem pendidikan yang menggunakan aplikasi elektronik untuk mendukung belajar mengajar dengan media Internet, jaringan komputer,maupun komputer standalone".

Colin dan Britain \& Liber, mendefinisikan $e$ learning sebagai lingkungan pembelajaran virtual sebagai paket perangkat lunak yang diinstal dalam server untuk mengatur administrasi proses pembelajaran (interaksi, akses informasi, diskusi, serta dukungan lainnya) ke dalam lingkungan yang terintegrasi.

Komponen yang membentuk E-learning

- Infrastruktur e-Learning: Infrastruktur eLearning dapat berupa personal computer (PC), jaringan komputer, internet dan perlengkapan multimedia.
- Sistem dan Aplikasi e-Learning: Sistem perangkat lunak yang mem-virtualisasi proses belajar mengajar konvensional

- Konten e-Learning: Konten dan bahan ajar yang ada pada e-Learning system (Learning Management System)

\section{2 eReadiness}

Kesiapan teknologi (technology readiness/TR) tidak melihat apakah seseorang menguasai atau tidak terhadap teknologi, melainkan merupakan sebuah kecenderungan seseorang untuk menerima dan menggunakan teknologi dalam menyelesaikan pekerjaannya. Readiness (Kesiapan) mempunyai banyak pembagian, seperti;

a. E-Learning Readiness sebagai "kesiapan mental atau fisik suatu organisasi untuk suatu pengalaman pembelajaran". Model ELR dirancang untuk menyederhanakan proses dalam memperoleh informasi dasar yang diperlukan dalam mengembangkan e-learning

b. Technology Readiness adalah keseluruhan kondisi seseorang yang membuatnya siap untuk memberi respon/jawaban di dalam cara tertentu terhadap suatu situasi. Penyesuaian kondisi pada suatu saat akan berpengaruh pada atau kecendrungan untuk memberi respon. Kondisi mencakup setidak-tidaknya 3 aspek, yaitu: (a) kondisi fisik, mental, dan emosional; (b) motif dan tujuan; dan (c) keterampilan dan pengetahuan yang telah dipelajari.

c. Technology Readiness Index merupakan indeks untuk mengukur kesiapan pengguna terhadap sebuah teknologi baru. TRI menggunakan serangkaian pernyataan kepercayaan/keyakinan dalam melakukan survei untuk mengukur secara menyeluruh tingkat kesiapan teknologi dari individu, dan merupakan alat dalam studi adopsi teknologi.

Merujuk Parasuraman, TRI digunakan untuk mengukur kesiapan pengguna dalam menggunakan teknologi baru dengan indikator empat variabel kepribadian yaitu:

a. Optimisme (optimism) Sikap pandang positif terhadap teknologi dan percaya bahwa teknologi akan meningkatkan kontrol, fleksibilitas, dan efisiensi dalam kehidupan

b. Inovatif (innovativeness) sebagai "tingkat dimana individu atau unit pengguna lain menggunakan ide-ide baru relatif lebih awal dibandingkan dengan anggota lain dari sistem tersebut

c. Ketidaknyamanan (discomfort) Memiliki sikap sulit mengontrol dan cenderung kewalahan berhadapan dengan teknologi baru.

d. Ketidakamanan (insecurity) Memiliki kecurigaan terhadap keamaanan teknologi dan alasan keamanan data pribadi. 


\section{METODOLOGI}

Penelitian ini menggunakan jenis penelitian survei, yaitu metode pengumpulan informasi dengan menyampaikan serangkaian pertanyaan yang telah diformulasikan sebelumnya dan urutan tertentu dalam sebuah kuesioner terstruktur kepada satu sampel individu yang dipilih untuk menjadi wakil sebuah populasi terdefenisi. Variabel yang digunakan dalam kuesioner berdasarkan variabel yang terdapat dalam model TRI. Adapun variabel dan dimensi variabel yang akan diteliti adalah sebagai berikut:

Table 1. Tabel dimensi variabel

\begin{tabular}{|c|c|c|}
\hline Variabel & & Dimensi Variabel \\
\hline Optimisme & 2) & $\begin{array}{l}\text { Kepercayaan dalam } \\
\text { meningkatkan kontrol. } \\
\text { Fleksibilitas dan efisien } \\
\text { dalam penggunaan } \\
\text { teknologi. }\end{array}$ \\
\hline Inovatif & 1) & $\begin{array}{l}\text { Penggerak dalam } \\
\text { menggunakan teknologi } \\
\text { terbaru. }\end{array}$ \\
\hline $\begin{array}{l}\text { Ketidaknya } \\
\text { manan }\end{array}$ & $\begin{array}{l}\text { 1) } \\
\text { 2) }\end{array}$ & $\begin{array}{l}\text { Kebutuhan untuk } \\
\text { mengontrol. } \\
\text { Rasa Kelawahan. }\end{array}$ \\
\hline $\begin{array}{l}\text { Ketidak- } \\
\text { amanan }\end{array}$ & 1) & $\begin{array}{l}\text { Ketidak percayaan } \\
\text { terhadap teknologi } \\
\text { karena alasan keamanan } \\
\text { dan privasi. }\end{array}$ \\
\hline
\end{tabular}

Skala pengukuran yang digunakan mengacu pada tipe skala Likert yang dikodekan dalam 1, 2, 3, 4, dan 5. Penentuan tingkat kesiapan organisasi dalam kesiapan penerapan e-learning didasarkan pada hasil penelitian Aydm dan Tasci, yang dapat diilustrasikan pada gambar 1 .

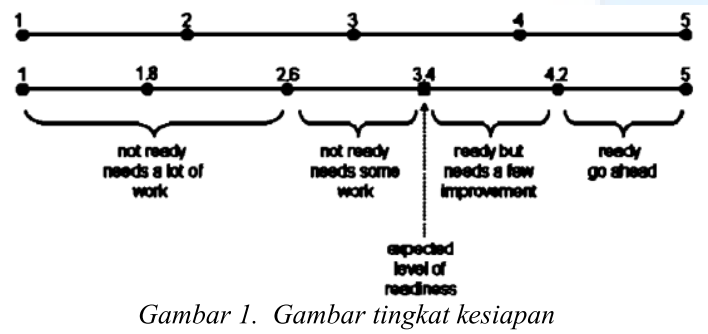

$1-2,6=$ Tidak ada kesiapan dan butuh kerja keras untuk mencapai keberhasilan

2,7-3,4 = Belum siap dan memerlukan beberapa kerja untuk mencapai keberhasilan

3,5-4,2 = Siap tetapi masih memerlukan sedikit perbaikan

4,3-5 = Benar-benar siap untuk implementasi
Tahap pengumpulan data dilakukan dengan wawancara, uji validitas dan reabilitas kuesioner dan penyebaran kuesioner. Tahap pengolahan data menggunakan aplikasi SPSS 20.00. analisa yang dilakukan menggunakan statistic deskriptif.

\section{HASIL dan PEMBAHASAN}

Populasi pada penelitian ini adalah seluruh Mahasiswa/I Fakultas Sains dan Teknologi yang berjumlah 7318 orang dan seluruh Dosen Fakultas Sains dan Teknologi yang berjumlah 129 orang yang merupakan pengguna E-learning UIN Suska Riau. Teknik sampling menggunakan tabel kracie deMorgan. Sehingga diperoleh sampel dalam penelitian ini adalah 155 orang responden, yang terdiri dari 56 orang dosen dan 99 orang mahasiswa/i. Pengambilan data dilakukan melalui survei kusioner. Data yang digunakan untuk penelitian meliputi data awal yang berguna untuk merumuskan masalah dan data primer yang digunakan untuk menilai kesiapan e-learning tersebut. Data primer diambil dari populasi penelitian melalui penyebaran kuesioner untuk responden dari dosen, mahasiswa yang terpilih menggunakan instrumen kuesioner.

\subsection{Hasil Kuesioner}

Rekapitulasi hasil Kuesioner Dosen dan Mahasiswa/I secara keseluruhan dapat dilihat pada tabel berikut ini :

Table 2. Tabel hasil Kuesioner

\begin{tabular}{lccc}
\hline Responden & $\begin{array}{c}\text { Skor Total } \\
\text { Yang Dicapai } \\
\text { Secara } \\
\text { Keseluruhan }\end{array}$ & $\begin{array}{c}\text { Skor } \\
\text { Kriterium } \\
\text { (Skor }\end{array}$ & (\%) \\
Ideal) & \\
\hline Dosen & 6938 & 10080 & 68,83 \\
Mahasiswa & 11724 & 17820 & 65,79 \\
\hline
\end{tabular}

Untuk menghitung total skor, dihitung berdasarkan hasil dari skoring penilaian yang ada di kuesioner. Dari tabel diatas dapat dilihat bahwa persentase untuk Dosen adalah sebesar 68,83\% dengan skor kriterium (Skor ideal) $=10080$, dan skor total yang dicapai secara keseluruhan = 6938. Sedangkan Mahasiswa/I dengan persentase sebesar 65,79\%, dengan skor kriterium (Skor ideal) $=17820$, dan skor total yang dicapai secara keseluruhan $=11724$.

\subsection{Hasil Analisa}

Berdasarkan hasil penyebaran kuesioner yang telah menggunakan data valid, tahap selanjutnya dilakukan pengolahan data dengan mengelompokkan data sesuai variabel yang ditetapkan. Dengan menggunakan statistic deskriptif, maka data dari setiap kelompoknya dicari nilai rataratanya dari seluruh variabel yang telah dikelompokan. 
Dengan menggunakan kriteria indeks yang telah ditetapkan oleh Aydin Tascii, maka dapat ditentukan nilai tingkat kesiapan penerapan elearning di fakutas Sains dan Teknologi adalah 3,36 yang artinya Not Ready, membutuhkan/memerlukan persiapan beberapa aspek untuk mencapai keberhasilan penerapan e-learning. Untuk setiap variabel didapat tingkat kesiapannya adalah variabel Optimisme dosen sebesar 3,70 , variabel Inovatif dosen sebesar 3,40, variabel ketidak-nyamanan dosen sebesar 3,46 dan variabel ketidak-amanan dosen sebesar 3,16, sedangkan untuk mahasiswa variabel Optimisme mahasiswa sebesar 3,51, variabel Inovatif mahasiswa sebesar 3,22, variabel Ketidak-nyamanan mahasiswa 3,23 dan variabel ketidak-amanan mahasiswa sebesar 3,16. Gambaran dari hasil pengukuran tingkat kesiapan penerapan elearning dapat dilihat pada gambar dibawah ini.

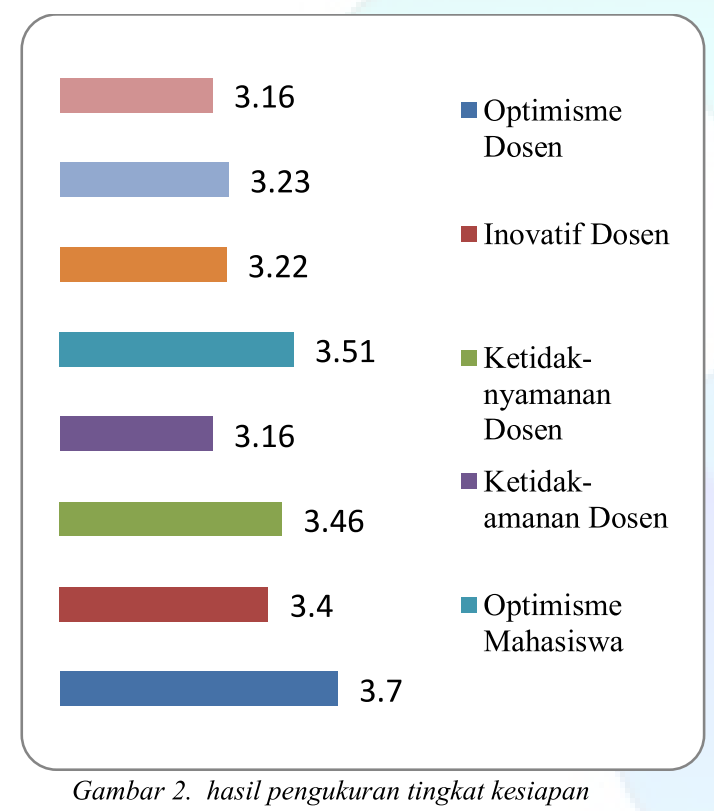

Tingkat kesiapan penerapan elearning dapat siap pada optimism pengguna. Baik pengguna dosen dan mahasiswa optimis dapat menggunakan elearning. Namun masih diperlukan perbaikan. Perbaikan yang perlu dilakukn untuk meningkatkan keinginan pengguna menggunakan elearning. Fitur - fitur yang ada saat ini masih dirasa kurang nyaman digunakan sehingga pengguna merasa kurang siap dalam menggunakannya. Factor keamanan dari elearning juga menjadi penyebab belum siapnya pengguna dalam menggunakan elearning.

\section{SIMPULAN dan SARAN}

Tingkat kesiapan penerapan e-learning pada Fakultas Sains dan Teknologi secara keseluruhan dapat disimpulkan berada pada tingkatan not ready. Berdasarkan hasil pengolahan data yang telah dilakukan, kesimpulan yang diperoleh dari penelitian ini adalah sebagai berikut :

Tingkat kesiapan penerapan e-learning pada fakultas sains dan teknologi

a. Untuk user sebagai dosen tingkat kesiapan variabel optimisme sebesar 3,70 dikatakan sudah siap untuk penerapan e-learning tetapi tetap menginovasi diri agar penerapan elearning lebih baik di masa yang akan datang. Variabel Inovatif sebesar 3,40 yang berarti not ready, memerlukan beberapa kerja untuk mencapai keberhasilan. Variabel ketidaknyamanan sebesar 3,46 artinya ready tetapi masih memerlukan sedikit perubahan. Variabel ketidak-amanan sebesar 3,16 not ready, memerlukan beberapa kerja untuk mencapai keberhasilan.

b. Untuk user sebagai mahasiswa tingkat kesiapan variabel Optimisme sebesar 3,51 ready, tapi masih memerlukan sedikit perbaikan. Variabel Inovatif sebesar 3,22 not ready, memerlukan beberapa kerja untuk mencapai keberhasilan. Variabel Ketidaknyamanan 3,23 not ready, memerlukan beberapa kerja untuk mencapai keberhasilan. Variabel ketidak-amanan sebesar 3,16 not ready, memerlukan beberapa kerja untuk mencapai keberhasilan.

\section{DAFTAR RUJUKAN}

Aydm, Gengiz Hakan. 2005. "Measuring Readinesss for e-Learning: Reflection from Emerging Country". Educational Technology and Society Journal, 8(4), pp. 244-257.

Bramanti F. L., 2009. "Pengukuran Kesiapan Organisasi Untuk Membangun dan Mengimplementasikan e-Learning, Studi Kasus: Universitas Achmad Yani,”.

Chapnick. Are you ready for E-Learning? ELearning readiness assessment. 2000. Diakses pada tanggal 17 Mei 2013 dari http://www.learningcircuits.org/2000/nov20 00/Chapnick.htm.

Guritno, Suryo, dkk. 2011. "Theory And Application of IT Research". Andi Publisher, Yogyakarta..

Hariyanti, Eva, dkk. "Pengukuran E-Learning Readiness Untuk Mendukung Keberhasilan Pengembangan E-Learning (Studi Kasus : Fst-Universitas Airlangga)”. Surabaya.

Jogiyanto, HM. 2005. "Analisa dan Desain Sistem Informasi". Andi Offset, Yogyakarta.

Kadir, Abdul dan Terra Ch. Triwahyuni. 2003. Pengenalan Teknologi Informasi. Andi Offset. Yogyakarta..

Parasuraman, A. 2000. Technology readiness index (TRI): A multiple-item scale to 
Angraini, dkk., Pengukuran Tingkat Kesiapan Penerapan E-Learning Menggunakan TRI (Technology..

measure readiness to embrace new technologies, Journal of Service Research, 2 (4), 307-320..

Prayitno, Deden, dkk. 2013. "Pengukuran Kesiapan Sumberdaya Pembelajaran Pada Implementasi Pendidikan Jarak Jauh (ELearning Readiness) di IKPIA Perbanas Studi Kasus Fakultas FTI". ICEM 2013. Yogyakarta.

Priyanto. "Model E-Learning Readiness Sebagai Strategi Pengembangan E-Learning”. Yogyakarta.

Priyatno, 2012. Duwi. "Belajar Cepat Olah Data Statistik Dengan SPSS". Andi Offset, Yogyakarta.
Riduwan. 2011. "Skala Pengukuran VariabelVariabel Penelitian". Alfabeta. Bandung.

Sugiyono. 2010. Metode Penelitian Kuantitatif Kualitatif dan $R \& D$. Alfabeta. Bandung..

Walczuch., dkk. 2007. Information \& Management 44, 206-215. Maastricht University, The Netherlands..

Y. M. Florestiyanto, 2012. "Evaluasi Kesiapan Pengguna Dalam Adopsi Sistem Informasi Terintegrasi Di Bidang Keuangan Menggunakan Metode Technology Readiness Index,". 